\title{
Uterine niche after cesarean section: a review of diagnostic methods
}

\author{
Joanna Budny-Winska®, Michal Pomorski®i \\ $2^{\text {nd }}$ Department of Gynaecology and Obstetrics, Wroclaw Medical University, Wroclaw, Poland
}

\begin{abstract}
The consequence of each cesarean section is the uterine scar formation. In some patients, uterine scar after cesarean section heals incompletely and as a result, the uterine niche is formed. Most of the small niches are asymptomatic, but the large cesarean scar niches in nonpregnant women may cause a cesarean scar syndrome, which manifest itself as abnormal uterine bleeding, dysmenorrhea and secondary infertility. Among pregnant women, the presence of large niches may be associated with potentially life-threatening consequences, such as cesarean scar dehiscence and uterine rupture, placenta accreta spectrum disorders, placenta previa, cesarean scar pregnancy. Due to the possibility of dangerous consequences related to the occurrence of a uterine niche, in recent years many studies have focused on the term of cesarean scar niche, its risk factors, diagnostic methods and treatment options. Uterine niche can be examined using two- or three-dimensional transvaginal ultrasonography, as well as two- and three-dimensional sonohysterography, hysterosalpingography, hysteroscopy or magnetic resonance imaging. However, neither of the above diagnostic method is considered as the "gold standard". There are no unambiguous guidelines on some aspect concerning the diagnosis of cesarean scar niche.

The aim of this study is to analyze and describe the diagnostic methods of cesarean section niche.
\end{abstract}

Key words: uterine niche; cesarean section niche; diagnostic methods; ultrasonography; sonohysterography

Ginekologia Polska 2021; 92, 10: 726-730

\section{INTRODUCTION}

In recent years, many studies have focused on the term of uterine niche after cesarean section. It is well known that the consequence of each cesarean section is the formation of uterine scar. In $50-70 \%$ of patients after cesarean section, a niche develops due to defective tissue healing [1, 2] It is defined as myometrial indentation at the site of the cesarean section scar with a depth of at least $2 \mathrm{~mm}$ [3].

Most of the small niches are asymptomatic. The clinical symptoms related to the presence of large uterine niche, and so-called cesarean scar syndrome includes abnormal uterine bleeding, dysmenorrhea and secondary infertility [4-6]. Obstetric complications of large cesarean scar niche in pregnancy may pose a risk of serious consequences because they are associated with scar dehiscence and uterine rupture, placenta accreta spectrum disorders, placenta previa, cesarean scar pregnancy $[1,7,8]$. Therefore, it is so important to early and correctly diagnose the uterine niche and implement an appropriate management, in cases requiring treatment.
Uterine niche can be examined using two- or three-dimensional transvaginal ultrasonography, as well as two- and three-dimensional sonohysterography [9], hysterosalpingography, hysteroscopy or magnetic resonance imaging [2]. However, neither of the above diagnostic method is considered as the "gold standard".

The aim of this study is to analyze and describe the diagnostic methods of cesarean section niche.

\section{TRANSVAGINAL ULTRASOUND (TVUS)}

Transvaginal ultrasonography is the initial and least invasive diagnostic method used to evaluate the integrity of the uterus wall. The cesarean section scar may take the form of an isolated niche, a niche with fibrosis, an isolated fibrosis [10]. In TVUS, small niches may not be visible, or their parameters may be underestimated [11, 12].

There were no uniform standards for the uterine niche's assessment.

In 2007, in the study entitled “Ultrasonographic analysis of cesarean scar features in nonpregnant uterus" for the

\footnotetext{
Corresponding author:

Joanna Budny-Winska

$2^{\text {nd }}$ Department of Gynaecology and Obstetrics, Wroclaw Medical University, 213 Borowska St, 50-556 Wroclaw, Poland

e-mail:joanna.budny91@gmail.com
} 
first-time standardized ultrasound evaluation of the uterine niche was presented [13]. In 2012, the same parameters were introduced for ultrasound examination of pregnant uterus by Naji et al. [14].

In 2013, Tower et al. proposed a uterine niche classification based on RMT and RMT/adjacent myometrial thickness (AMT) ratio as the only ultrasound niche features [15].

In 2019, the guidelines for sonographic examination of uterine niche in non-pregnant women according to a modified Delphi procedure were introduced [3]. According to these guidelines, basic niche evaluation includes the measurement of its length, depth, width, RMT, AMT, along with documentation and measurement of the present niche's branches (Fig. 1). RMT, length, depth of the niche should be measured in the sagittal plane, while the transverse plane is used to measure the width and identify its branches. The assessment of the distance between the niche and the vesicovaginal fold, and between the niche and the external os of the cervix provide an extended niche assessment, which is helpful in surgical strategy planning. The use of Doppler imaging is not obligatory but can be useful in differentiating uterine niches from hematomas, adenomyomas, and fibrotic tissue. This publication also introduces the classification of niches according to their shape, with a division into simple niche, simple niche with one branch, complex niche [3].

\section{SONOHYSTEROGRAPHY (SHG)}

Sonohysterography is a diagnostic method in which transvaginal ultrasonography of the uterus is enhanced by instillation of fluid into the uterine cavity to provide an anechoic contrast medium. It may be the sterile saline solution (SCSH) or gel (GIS).

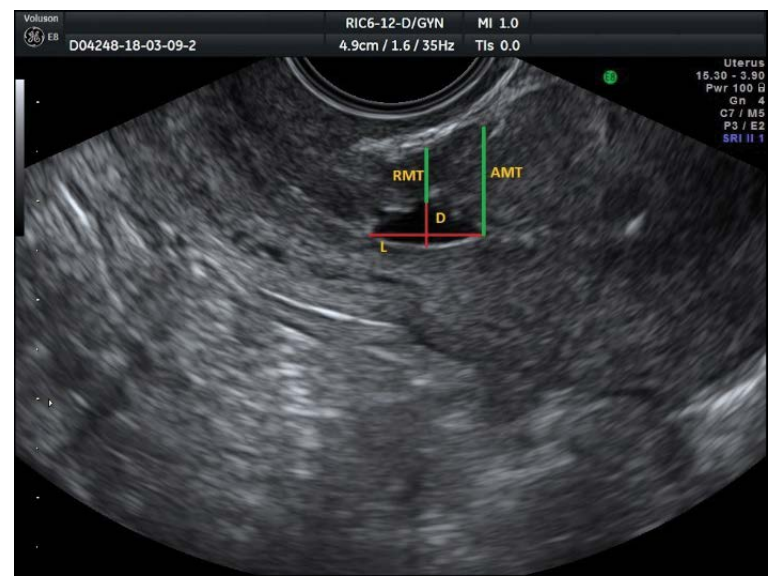

Figure 1. Basic evaluation of the simple niche according to the study of Jordans IPM, et al. "Sonographic examination of uterine niche in non-pregnant women: a modified Delphi procedure" [3]; L — length; D - depth; RMT — residual myometrial thickness; AMT — adjacent myometrial thickness
During sonohysterography the same parameters of the cesarean scar niche as with TVUS are measured, but it enables better visualization and demarcation of isthmocele. Additionally, it has increased sensitivity and specificity for the detection of uterine niches by enhancing the isthmocele and allowing its dynamic evaluation. Compared to transvaginal ultrasonography, it detects more niches [16, 17] and more of them are classified as large [18]. It is more invasive examination than TVUS and carries a low risk of complications (such as infections). During this examination, the cesarean scar niche may also be overestimated (about 1-2 $\mathrm{mm}$ ) due to its overstretching by flushed into uterine cavity fluid [15]. The study by A. El-Mazny et al. showed that the detectability of the cesarean scar niche in SHG compared to hysteroscopy is $96 \%$, while for intrauterine adhesions $91 \%$, therefore SHG is a good alternative in the assessment of the uterine cavity [19].

\section{THREE-DIMENSIONAL (3D) IMAGING}

All niche parameters and its volume could be measured using 3D ultrasonography. The study by M. Alalfy showed that $3 \mathrm{D}$ sonohysterography is as accurate in assessing the uterine niche after cesarean section as 2D sonohysterography. However, the use of $3 \mathrm{D}$ sonography provide better characterization of the cesarean scar niche, because of superior evaluation of the RMT and niche width before the Intracytoplasmic Sperm Injection [20].

In the study by A. Ludwin et al. [21] to improve the reliability of volume estimation and morphological assessment of cesarean niche, as well as its classification (see below), the 3D-SCSH in conjunction with Sonography-based Automated Volume Count software (SonoHysteroAVC) or Virtual Organ Computer-aided AnaLysis (VOCAL) was used.9 Another study used 3D transvaginal ultrasonography to create a uterine niche's model and the VOCAL program to determine its volume (Fig. 2).

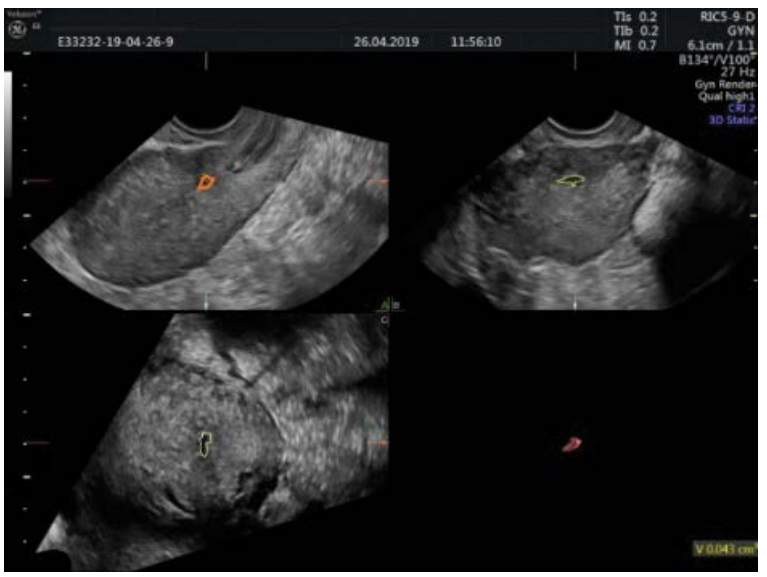

Figure 2. 3D model of cesarean scar niche 


\section{HISTEROSALPINGOGRAPHY (HSG)}

Hysterosalpingography is a radiologic examination mainly used in the diagnosis of female factor infertility. It is done under fluoroscopy to visualize the uterine cavity and lumen of the fallopian tubes. This examination can identify the cesarean scar niches that can be the cause of secondary infertility after cesarean section. In the study by K. Suprapaneni and J. E Silberzweig, among 148 patients with history of cesarean section and technically adequate hysterosalpingograms, $60 \%$ of them had uterine cesarean scar niches [22].

Isthmocele in HSG is visualized as a leakage of contrast from the uterine cavity into a myometrial defect. HSG also allows classification of the uterine niches in terms of its shape and location [23].

The limitation of this diagnostic method is its inability to accurately measure RMT and other parameters of the niche. Moreover, if blood or mucus is accumulated in the isthmocele, HSG may not clearly identify the uterine niche [24].

\section{MAGNETIC RESONANCE IMAGINING (MRI)}

$M R I$ relies upon the magnetic properties of living tissue. It detects the magnetic moment created by single protons in hydrogen atoms.

The use of MRI allows to determine all parameters of the niche, as well as niche and uterine cavity content on the sagittal T2-weighted views [2].

In study Marotta et al. [25] it has been shown that RMT measurements in MRI were related to those assess through TVUS.

MRI of the cesarean scar niche is not widely used due to its cost and availability. However, because it provides a comprehensive insight into the anatomy of the pelvis and its pathology, thanks to a higher tissue resolution and a wider field of view in comparison to TVUS, it is particularly useful in planning surgery, especially if there are other pathological conditions of the female's reproductive organs.

\section{HYSTEROSCOPY}

Diagnostic hysteroscopy is the "gold standard" in the diagnosis of uterine abnormalities. During this examination, the presence of the cesarean section scar niche can be directly visualized and confirmed [18, 26]. So far, the classification of the niches in hysteroscopic examination has not been described. The uterine niche in hysteroscopic examination is defined in various ways, e.g., a cavity with fibrotic ring, a pouch-like defect, a diverticulum with/without mucosa, a dome-shaped niche with nodules of endometrial hyperplasia/vascular hyperplasia [27]. There are no data in the literature on the relationship between the appearance of the uterine niche and the presence of clinical symptoms.

During hysteroscopy, which was performed in a group of women with abnormal uterine bleeding after cesarean sec- tion, the areas of profuse vascularization or polyps in niche were present $[25,28]$. Hysteroscopy can also show the invagination of the myometrium with residual blood, which may correspond to the menstrual blood accumulating in the niche or related to endometriosis [28].

Histological analysis of samples taken after hysteroscopic treatment of uterine niches showed the presence of chronic inflammatory infiltration of the endocervix, fibrosis and necrosis, adenomyosis and polyps $[6,26,29]$

\section{WHAT IS THE OPTIMAL TIMING FOR THE CESAREAN SECTION NICHE ASSESSMENT?}

There are no unambiguous guidelines regarding the time after the cesarean section in which the uterine scar should be assessed.

In the study of L.F. van der Voet et al. [30] differences in cesarean scar niche's parameters dimensions were shown among patients, in whom the niche was the first time examined 6-12 weeks after the cesarean section, compared to the results of the examination performed one year after surgery. Contrary to changing uterine scar parameters, the incidence of uterine niche was unchanged. Other studies in which uterine niches were re-evaluated 6-24 months apart also showed a decrease in RMT over time after cesarean section [31].

The reduction in RMT or AMT /RMT ratio may be caused due to tissue reactions or a reduction in uterine muscle swelling during the healing process. Another theory involves the interaction of the uterus with adhesions between the uterus and the abdominal wall, resulting in an increase in niche depth and a decrease in RMT [32]. Moreover, uterine contractions can affect the RMT, and the accumulation of menstrual blood in the niche can increase the pressure on RMT, causing the change on its dimension [30].

\section{IN WHICH PHASE OF MENSTRUAL CYCLE SHOULD WE ASSESS UTERINE NICHE?}

There are no clear guidelines regarding the phase of the menstrual cycle in which a cesarean scar should be assessed [3]. According to some authors, the best time to perform an ultrasound examination is when the endometrial thickness is the smallest, it means immediately after the menstruation [33]. In another publication, the best time is during/after a few days after the menstruation [20]. According to the modified Delphi protocol, the ultrasound niche evaluation between 7.-14. cycle day may prevent the need for additional infusion fluid due to its natural intrauterine occurrence in the midfollicular phase [3].

A 3D-sonohisterography evaluation of the niche should be performed between the 17-25 day of the menstrual cycle because the cervical mucous during the preovulatory phase and blood deposits after menstruation may mix with the infused saline, which will deteriorate the quality of imaging [9]. 


\section{HOW CAN WE CLASSIFY THE CESAREAN SECTION NICHES?}

The literature lacks in uniform classification of cesarean scar niche. The first classification system of uterine niches was proposed by Gubbini in 2011 [6]. This classification was based on the measurement of the depth, base of the isthmocele and on calculation of its triangular area. This allowed to classify the uterine niches after cesarean section according to the size of its area.

In other studies, the large niche is when it penetrates to a depth of at least $50 \%$ or $80 \%$ of the uterine muscle or when RMT is $\leq 2.2 \mathrm{~mm}$ in transvaginal sonography and $\leq 2.5 \mathrm{~mm}$ in sonohysterography. In the situation, when there is no remaining defect over the isthmocele, it is a total defect of the uterine niche [34].

In the classification (VTS system) of cesarean section niches, which was proposed by A. Ludwin et al., the niche volume, RMT, presence supplementary features (niche's branches, urinary bladder not covering the niche and suspicion of deeply infiltrating endometriosis in the niche) were assessed [9]. Depending on the obtained total score, the niche is classified as probably clinically irrelevant or relevant.

\section{CONCLUSIONS}

There are still no unambiguous diagnostic and classification standards for uterine niches after cesarean section. Due to the growing number of cesarean sections and thus the growing problem of the increasing number of large uterine niches, which pose a risk of serious health consequences, it is necessary to create standardized diagnostic and therapeutic algorithms.

\section{Conflict of interest}

The authors state that there are no conflicts of interest to disclose.

\section{REFERENCES}

1. Pomorski M, Fuchs T, Rosner-Tenerowicz A, et al. Standardized ultrasonographic approach for the assessment of risk factors of incomplete healing of the cesarean section scar in the uterus. Eur J Obstet Gynecol Reprod Biol. 2016; 205: 141-145, doi: 10.1016/j.ejogrb.2016.08.032, indexed in Pubmed: 27591715.

2. Setubal A, Alves J, Osório F, et al. Treatment for uterine isthmocele, a pouchlike defect at the site of a cesarean section scar. J Minim Invasive Gynecol. 2018; 25(1):38-46, doi: 10.1016/j.jmig.2017.09.022, indexed in Pubmed: 29024799.

3. Jordans IPM, de Leeuw RA, Stegwee SI, et al. Sonographic examination of uterine niche in non-pregnant women: a modified Delphi procedure. UItrasound Obstet Gynecol. 2019; 53(1): 107-115, doi: 10.1002/uog.19049, indexed in Pubmed: 29536581.

4. Vervoort A, Vissers J, Hehenkamp W, et al. The effect of laparoscopic resection of large niches in the uterine caesarean scar on symptoms, ultrasound findings and quality of life: a prospective cohort study. BJOG. 2018; 125(3): 317-325, doi: 10.1111/1471-0528.14822, indexed in Pubmed: 28703935.

5. Pomorski M, Fuchs T, Rosner-Tenerowicz A, et al. Sonographic evaluation of surgical repair of uterine cesarean scar defects. J Clin Ultrasound. 2017; 45(8): 455-460, doi: 10.1002/jcu.22449, indexed in Pubmed: 28186617.
6. Gubbini G, Centini G, Nascetti D, et al. Surgical hysteroscopic treatment of cesarean-induced isthmocele in restoring fertility: prospective study. J Minim Invasive Gynecol. 2011; 18(2): 234-237, doi: 10.1016/j. jmig.2010.10.011, indexed in Pubmed: 21354070.

7. Silver RM. Abnormal placentation: placenta previa, vasa previa, and placenta accreta. Obstet Gynecol. 2015; 126(3): 654-668, doi: 10.1097/AOG.0000000000001005, indexed in Pubmed: 26244528.

8. Clark EAS, Silver RM. Long-term maternal morbidity associated with repeat cesarean delivery. Am J Obstet Gynecol. 2011; 205(6 Suppl): S2-10, doi: 10.1016/j.ajog.2011.09.028, indexed in Pubmed: 22114995.

9. Ludwin A, Martins WP, Ludwin I. Evaluation of uterine niche by three-dimensional sonohysterography and volumetric quantification: techniques and scoring classification system. Ultrasound Obstet Gynecol. 2019; 53(1): 139-143, doi: 10.1002/uog.19181, indexed in Pubmed: 30039641.

10. Al Naimi A, Wolnicki B, Mouzakiti N, et al. Anatomy of the sonographic post-cesarean uterus. Arch Gynecol Obstet. 2021 [Epub ahead of print], doi: 10.1007/s00404-021-06074-y, indexed in Pubmed: 33891206.

11. Bij de Vaate AJM, Brölmann HAM, van der Voet LF, et al. Ultrasound evaluation of the Cesarean scar: relation between a niche and postmenstrual spotting. Ultrasound Obstet Gynecol. 2011;37(1): 93-99, doi: 10.1002/uog.8864, indexed in Pubmed: 21031351.

12. Yao M, Wang W, Zhou J, et al. Cesarean section scar diverticulum evaluation by saline contrast-enhanced magnetic resonance imaging: The relationship between variable parameters and longer menstrual bleeding. J Obstet Gynaecol Res. 2017; 43(4): 696-704, doi: 10.1111/jog.13255, indexed in Pubmed: 28168867.

13. Zimmer M, Pomorski M, Fuchs T, et al. Ultrasonograficzna ocena blizny po cieciu cesarskim w macicy nieciezarnej [Ultrasonographic analysis of cesarean scars features in nonpregnant uterus]. Ginekol Pol. 2007; 78(11): 842-846.

14. Naji O, Abdallah Y, Bij De Vaate AJ, et al. Standardized approach for imaging and measuring Cesarean section scars using ultrasonography. Ultrasound Obstet Gynecol. 2012; 39(3): 252-259, doi: 10.1002/uog.10077, indexed in Pubmed: 21858885

15. Tower AM, Frishman GN. Cesarean scar defects: an underrecognized cause of abnormal uterine bleeding and other gynecologic complications. J Minim Invasive Gynecol. 2013; 20(5): 562-572, doi: 10.1016/j. jmig.2013.03.008, indexed in Pubmed: 23680518.

16. Tulandi T, Cohen A. Emerging manifestations of cesarean scar defect in reproductive-aged women. J Minim Invasive Gynecol. 2016; 23(6): 893 902, doi: 10.1016/j.jmig.2016.06.020, indexed in Pubmed: 27393285.

17. Rasheedy R, Sammour H, Elkholy A, et al. Agreement between transvaginal ultrasound and saline contrast sonohysterography in evaluation of cesarean scar defect. J Gynecol Obstet Hum Reprod. 2019; 48(10): 827831, doi: 10.1016/j.jogoh.2019.05.013, indexed in Pubmed: 31077871.

18. Fabres C, Aviles G, De La Jara C, et al. The cesarean delivery scar pouch: clinical implications and diagnostic correlation between transvaginal sonography and hysteroscopy. J Ultrasound Med. 2003; 22(7):695-700; quiz 701, doi: 10.7863/jum.2003.22.7.695, indexed in Pubmed: 12862268.

19. El-Mazny A, Abou-Salem N, El-Khayat W, et al. Diagnostic correlation between sonohysterography and hysteroscopy in the assessment of uterine cavity after cesarean section. Middle East Fertility Society Journal. 2011; 16(1): 72-76, doi: 10.1016/j.mefs.2010.07.015.

20. Alalfy M, Osman OM, Salama $S$, et al. Evaluation of the cesarean scar niche in women with secondary infertility undergoing ICSI using 2D sonohysterography versus 3D sonohysterography and setting a standard criteria; alalfy simple rules for scar assessment by ultrasound to prevent health problems for women. Int J Womens Health. 2020; 12: 965-974, doi: 10.2147/IJWH.S267691, indexed in Pubmed: 33177887.

21. Budny-Winska J, Zimmer-Stelmach A, Pomorski M. Two- and three-dimensional transvaginal ultrasound in assessment of the impact of selected obstetric risk factors on cesarean scar niche formation: the case-controlled study. Ginekol Pol. 2021; 92(5): 378-382, doi: 10.5603/GP.a2021.0024, indexed in Pubmed: 33757154.

22. Surapaneni K, Silberzweig JE. Cesarean section scar diverticulum: appearance on hysterosalpingography. AJR Am J Roentgenol. 2008; 190(4): 870-874, doi: 10.2214/AJR.07.2916, indexed in Pubmed: 18356431.

23. Ahmadi F, Torbati L, Akhbari F, et al. Appearance of uterine scar due to previous cesarean section on hysterosalpingography: various shapes, locations and sizes. Iran J Radiol. 2013; 10(2): 103-110, doi: 10.5812/iranjradiol.5143, indexed in Pubmed: 24046789.

24. Sipahi $\mathrm{S}$, Sasaki $\mathrm{K}$, Miller CE. The minimally invasive approach to the symptomatic isthmocele - what does the literature say? A step-by-step primer on laparoscopic isthmocele-excision and repair. Curr Opin Obstet 
Gynecol. 2017; 29(4): 257-265, doi: 10.1097/GCO.0000000000000380, indexed in Pubmed: 28598911.

25. Marotta ML, Donnez J, Squifflet J, et al. Laparoscopic repair of post-cesarean section uterine scar defects diagnosed in nonpregnant women. J Minim Invasive Gynecol. 2013; 20(3): 386-391, doi: 10.1016/j. jmig.2012.12.006, indexed in Pubmed: 23357466.

26. Raimondo G, Grifone G, Raimondo D, et al. Hysteroscopic treatment of symptomatic cesarean-induced isthmocele: a prospective study. J Minim Invasive Gynecol. 2015; 22(2): 297-301, doi: 10.1016/j.jmig.2014.09.011, indexed in Pubmed: 25285773.

27. Connor ME, Clark J. Unusual Hysteroscopic situations: cesarean niche and retained placental tissue. In: Diagnostic and Operative Hysteroscopy. Cambridge University Press 2020: 196.

28. Chen YY, Tsai CC, Kung FT, et al. Association between hysteroscopic findings of previous cesarean delivery scar defects and abnormal uterine bleeding. Taiwan J Obstet Gynecol. 2019; 58(4): 541-544, doi: 10.1016/j. tjog.2019.05.020, indexed in Pubmed: 31307748.

29. Shapira M, Mashiach R, Meller N, et al. Clinical success rate of extensive hysteroscopic cesarean scar defect excision and correlation to histologic findings. J Minim Invasive Gynecol. 2020; 27(1): 129-134, doi: 10.1016/j. jmig.2019.03.001, indexed in Pubmed: 30858053.
30. van der Voet LF, Jordans IPM, Brölmann HAM, et al. Changes in the uterine scar during the first year after a caesarean section: a prospective longitudinal study. Gynecol Obstet Invest. 2018; 83(2): 164-170, doi: 10.1159/000478046, indexed in Pubmed: 28957798.

31. Bennich G, Rudnicki M, Wilken-Jensen C, et al. Impact of adding a second layer to a single unlocked closure of a Cesarean uterine incision: randomized controlled trial. Ultrasound Obstet Gynecol. 2016; 47(4): 417-422, doi: 10.1002/uog.15792, indexed in Pubmed: 26489989.

32. Vervoort AJ, Uittenbogaard LB, Hehenkamp WJK, et al. Why do niches develop in Caesarean uterine scars? Hypotheses on the aetiology of niche development. Hum Reprod. 2015; 30(12): 2695-2702, doi: 10.1093/humrep/dev240, indexed in Pubmed: 26409016.

33. Woźniak A, Pyra K, Tinto HR, et al. Ultrasonographic criteria of cesarean scar defect evaluation. J Ultrason. 2018; 18(73): 162-165, doi: 10.15557/JoU.2018.0024, indexed in Pubmed: 30451411.

34. Bij de Vaate AJM, van der Voet LF, Naji O, et al. Prevalence, potential risk factors for development and symptoms related to the presence of uterine niches following Cesarean section: systematic review. Ultrasound Obstet Gynecol. 2014;43(4): 372-382, doi: 10.1002/uog.13199, indexed in Pubmed: 23996650. 